Revista de Estudios Histórico-Jurídicos

[Sección historia del derecho indiano]

XXXIX (Valparaíso, Chile, 2017)

[pp. 173 - 193]

\title{
Matrimonio y derecho natural en Alonso de VERACRUZ (1507-1584)
}

[Marriage and natural rights according to Alonso de Veracruz (1507-1584)]

\author{
Anastasía Assimakópulos* \\ Sebastián CONTRERAs** \\ Universidad de los Andes, Chile
}

\section{RESUMEN}

En este trabajo se expone la doctrina de fray Alonso de Veracruz sobre el matrimonio natural. En Speculum coniugiorum, texto en que se basa nuestro trabajo y en el que el autor intenta destacar la racionalidad de los indios y la importancia de la diversidad cultural para el desarrollo integral de la persona, se hace frente al problema de la naturaleza del pacto esponsal a la luz de los principios de derecho natural y de la enseñanza de los grandes maestros de la Escolástica española.

\section{Palabras clave}

Ley natural - Matrimonio - Alonso de Veracruz.

\section{AbSTRACT}

In this paper the authors exposed the doctrine of Friar Alonso de Veracruz about natural marriage. In Speculum coniugiorum, work that aims to highlight the rationality of the Indians and the importance of cultural diversity for the development of the men, the Augustinian thinker clarify the issue of the nature of the spousal agreement on the base of the principles of natural law and the teaching of the great masters of the Spanish Scholastics.

\section{KEYWORDS}

Natural Law - Marriage - Alonso de Veracruz.

RECIBIDO el 22 de marzo y ACEPTADO el 3 de octubre de 2016

* Abogada. Doctora en Derecho, Universidad de los Andes, Chile. Licenciada en Derecho, Pontifica Universidad Católica de Chile. Licenciada en Derecho Canónico, Pontificia Universidad de la Santa Cruz, Roma. Profesora Asistente de derecho canónico, Universidad de los Andes, Chile. Mons. Álvaro del Portillo 12.455, Las Condes, Santiago, Chile. Correo electrónico: anastasia@uandes.cl.

** Doctor en Filosofía. Licenciado en Ciencias Sociales. Profesor de filosofía del derecho, Universidad de los Andes, Chile. Mons. Álvaro del Portillo 12.455, Las Condes, Santiago, Chile.

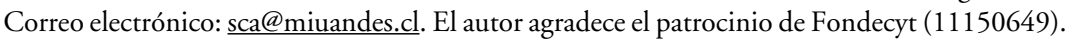




\section{INTRODUCCIÓN}

En este trabajo se expone la doctrina sobre el matrimonio natural de fray Alonso de Veracruz, uno de los principales autores de la Escolástica americana del siglo XVI. El matrimonio, como institución natural, es un pacto de vida entre un hombre y una mujer orientado a la procreación de los hijos y la ayuda mutua de los cónyuges. Así lo expone Alonso en su Speculum coniugiorum, publicado por primera vez en 1556. El trabajo se divide en cinco partes. En primer lugar, hacemos una breve presentación del autor, de su doctrina y contexto. En segundo lugar, se propone un examen del significado que tiene la ley natural en la obra de Veracruz, concepto que será clave para entender la teoría alonsina del matrimonio de los indios. En tercer lugar, se expone la reflexión alonsina acerca del matrimonio natural. En cuarto lugar, se tratan los elementos del pacto esponsal propuestos por Alonso de Veracruz. Por último, se trata el impedimento de consanguinidad. Cierran este trabajo unas breves conclusiones.

\section{EL AUTOR: SU DOCTRINA Y CONTEXTO}

El llamado a m paro de 1 o s in d i o ${ }^{1}$, fray Alonso de Veracruz, es una de las piezas centrales de la Escolástica americana. "Persona cualificada y docta" 2 , se ha dicho que en él "compiten la más alta virtud con la más exquisita y admirable doctrina" . Es padre de la filosofía de México y redactor del primer curso filosófico de Nueva España ${ }^{4}$-sus escritos fueron las primeras obras de filosofía salidas de prensas americanas ${ }^{5}-$.

Su actividad misionera lo hizo conocido como "el fraile más celoso de hábito

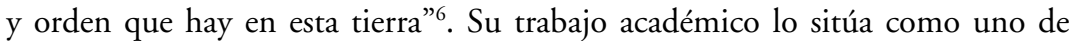
los fundadores de la Universidad de México $^{7}$ y como ejemplo del humanismo

\footnotetext{
${ }^{1}$ Basalenque, Diego, Historia de la provincia de San Nicolás Tolentino de Michoacán de la orden de nuestro padre san Agustin (México DF, Jus, 1963), p. 92.

2 Burrus, Ernest, The Writings of Alonso de la Vera Cruz (Rome, Jesuit Historical Institute, 1967-1976), 4, p. 262.

${ }^{3}$ Cervantes de Salazar, Francisco, México en 1554. Tres diálogos latinos (México DF, Unam, 2001), p. 10.

${ }^{4}$ Beuchot, Mauricio, Historia de la filosofía en el México colonial (Barcelona, Herder, 1997), pp. 124-125; Gracia, Jorge, Filosofía hispánica (Pamplona, Cuadernos de Anuario Filosófico, 1998), p. 66; Larroyo, Francisco, La filosofía iberoamericana (México DF, Porrúa, 1989), p. 40.

5 Díaz, Gonzalo, Hombres y documentos de la filosofía española (Madrid, CSIC, 1980), 1, p. 199.

${ }^{6}$ Declaración de Jorge Cerón Carvajal, alcalde de México (marzo de 1562), en Burrus, Ernest, The Writings, cit. (n. 2), 5, p. 268. Dice Beuchot que, aunque Alonso veía la religión cristiana como el mayor bien que se podía entregar a los indios, "siempre abogó por la suavidad en los métodos misionales, nunca por la violencia; y en cuanto a los encomenderos y esclavizadores, siempre luchó contra ellos". ВЕUСНOT, Mauricio, La querella de la conquista. Una polémica del siglo XVI (México DF, Siglo XXI, 2004), p. 90.

7 Beuchот, Mauricio, Filosofia y culturas novohispanas (México DF, Unam, 1998), pp. 17 ss.
} 
renacentista español ${ }^{8}$. Y su obra jurídica, que acá comentamos, lo ubica como el primer catedrático de derecho de gentes en México?.

Discípulo predilecto de Francisco de Vitoria -a quien se suele llamar Sócrates español-, su trayectoria filosófica está marcada por sus años como estudiante en las dos universidades más importante de la España del siglo XVI: Salamanca y Alcalá de Henares. En la universidad de Cisneros estudia gramática y retórica, y en Tormes, teología y filosofía. Es aquí donde conoce a Vitoria, con quien mantiene una estrecha amistad ${ }^{10}$.

Las ideas políticas de Veracruz son parte de la gran tradición de la Escolástica española. Eso explica que la reflexión alonsina sobre el matrimonio de los indios sea un desarrollo y aplicación de los principios generales sobre el matrimonio expuestos por los fundadores de la Escuela de Salamanca: el propio Francisco de Vitoria y fray Domingo de Soto, quien también fuera maestro de Veracruz en Salamanca.

$\mathrm{Al}$ igual que otros pensadores escolásticos, como Las Casas, Veracruz quiere destacar la racionalidad de los indios y conciliar los intereses y costumbres de los indígenas con los intereses y costumbres de los españoles. Pero, a diferencia de otros autores, como Vitoria, la opción filosófica del agustino está enriquecida por su experiencia como misionero y profesor en tierras americanas: en materia política y jurídica "el catedrático [Alonso] sacó sus propias conclusiones prácticas de aplicación a la crisis de la política colonial, avaladas por su experiencia y las pruebas de los hechos vividos con los mismos interesados. Y ésta fue su gran aportación. Aquí radica su originalidad. Nada parecido sucedió durante la primera conquista de las Indias"11.

Si bien las ideas políticas de Veracruz pueden situarse al interior de la Escolástica vitoriana, la filosofía alonsina tiene su propia lógica - "lo cual casa perfectamente con su carácter, siempre tan libre en todo lo intelectual e independiente de las corrientes de opinión"12-. Alonso entiende que la ciencia teológica (y también la filosofía) no consiste en repetir lo que dicen las autoridades, sino en buscar la

${ }^{8}$ Velasco, Ambrosio, Alonso de la Veracruz. La tradición humanista republicana, en Revista de la Universidad de México, 46 (2007), pp. 51-55.

9 Gómez Robledo, Antonio, El magisterio filosófico y jurídico de Alonso de la Veracruz (México DF, Porrúa, 1984), p. XLIV.

${ }^{10}$ Cerezo de Diego, Prometeo, Alonso de la Veracruz y su maestro Francisco de Vitoria, en Velasco, Ambrosio (editor), Fray Alonso de la Veracruz: universitario, humanista, cientifico y republicano (México DF, Unam, 2009), p. 21; Grijalva, Juan de, Crónica de la Orden de N.P.S. Agustín en las provincias de la Nueva España (México DF, Porrúa, 1985), p. 397. "Según todos los indicios, Veracruz debió ser uno de los discípulos predilectos de Vitoria y quizá uno de los que participaba en aquellas reuniones privadas (especie de tertulias académicas, como las llama Beltrán de Heredia) con los alumnos más aventajados, en las que se hablaba de los temas más candentes, ampliando las lecciones universitarias y donde aquellas mentes juveniles selectas eran deslumbradas por los afanes renovadores vitorianos”. BELDA PLANS, Juan, La Escuela de Salamanca y la renovación de la teología en el siglo XVI (Madrid, BAC, 2000), p. 875.

11 Pereña, Luciano, La Escuela de Salamanca, notas de identidad, en Gómez CAmacho, Francisco y Robledo, Ricardo (eds.), El pensamiento económico de la Escuela de Salamanca (Salamanca, Eusal, 1998), p. 55.

12 Saranyana, Josep-Ignasi, Grandes maestros de la teología. De Alejandría a México (siglos III alXVI) (Madrid, Atenas, 1994), p. 221. Es de notar que Veracruz fue un teólogo independiente, 
verdad de las cosas. Por eso, señala, "sin pasión y afición desordenada busquen la verdad en quien la hallaren"13. Luego, sobre la base de su formación salmantina, el agustino construye una teología "nada servil", que busca aplicar los principios comunes de la justicia natural a la compleja realidad misional americana. Su proyecto filosófico no es una doctrina española trasplantada al Nuevo Mundo, sino una genuina teología americana, que supera los límites del pensamiento vitoriano, y que pone a prueba ese espíritu de libertad que caracteriza a los pensadores escolásticos del siglo XVI ${ }^{14}$.

Alonso es un autor iusnaturalista y multiculturalista ${ }^{15}$. Asume la diversidad de culturas como una expresión de la racionalidad del hombre. Lejos de pensar que unas costumbres distintas convierten a los indios en amentes o irracionales, postula que la organización y existencia de funciones sociales diversas en los pueblos americanos es una prueba suficiente para suponer que en esos hombres existe capacidad política: "estos habitantes del Nuevo Mundo no sólo no son niños ni amentes, sino que a su manera son destacados, y hay entre ellos a lo menos algunos que a su manera son destacadísimos. I Esto es manifiesto: porque, antes de la llegada de los españoles, y ahora lo vemos con nuestros propios ojos, habia entre ellos magistraturas $y$ gobiernos y ordenanzas muy pertinentes; y tenian organización politica y régimen de gobierno, no sólo monárquico, sino también aristocrático; y tenían leyes, y castigaban a los malhechores, y asi también premiaban a los beneméritos de la república"16.

Puesto que los indios son racionales, conocen los principios de la ley natural, al menos los principios más universales. Tales principios rigen a todos los hombres y ordenan la vida política en dirección a la felicidad. Entre éstos está el primero de todos, "el bien hay que hacerlo y el mal hay que evitarlo", y otros como la regla de oro y "hay que vivir según la razón”. La unidad de los principios primeros se deriva de la unidad de la naturaleza, que es la misma en todos los hombres. Estos preceptos son la base del conocimiento práctico y son principios de otros principios más específicos. Se trata de los preceptos morales derivados, que son los responsables de la diversidad de costumbres de los hombres. La variabilidad de estos principios se debe a la variabilidad de la naturaleza humana, que no es

“aunque muy aficionado a Santo Tomás”. Illanes, José Luis y SARANYANA, Josep-Ignasi, Historia de la teología (Madrid, BAC, 1995), pp. 166-167.

${ }^{13}$ Burrus, Ernest, The Writings, cit. (n. 2), I, p. 93; SaranYana, Josep-Ignasi (n. 12), p. 214.

14 Belda Plans, Juan, cit. (n. 10), pp. 877-878.

15 Velasco, Ambrosio, Las ideas republicanas para una nación multicultural, en Ponce, Carolina (editora), Innovación y tradición en fray Alonso de la Veracruz (México DF, Unam, 2007), p. 70; Velasco, Ambrosio, Radicalización del republicanismo salmantino en México: de fray Alonso de la Veracruz a la independencia de México, en Aspe, Virginia y ZorrozA, Idoya (eds.), Francisco de Vitoria en la Escuela de Salamanca y su proyección en Nueva España (Pamplona, Eunsa, 2014), p. 180.

16 Veracruz, Alonso de, De dominio infidelium et iusto bello. Sobre el dominio de los infieles y la guerra justa (México DF, Unam, 2007), \$\$ 716-717. La defensa que hace el agustino de la racionalidad de los indios ha hecho que se lo compare con Las Casas, uno de los principales defensores de la causa indígena en el siglo XVI. Burrus, Ernest, Las Casas and Veracruz. Their Defense of the American Indians Compared, en Neue Zeitschrift für Missionswissenschaft, 22 (1966), pp. 201-212. 
inmóvil, como la divina. Por eso algunas cosas que convienen a los hombres no son iguales en todas partes. Es lo que ocurre con el matrimonio, pues los ritos y formas en que se expresa el consentimiento cambian de lugar en lugar ${ }^{17}$.

Así pues, Veracruz se propone estudiar la cuestión de la legitimidad de los matrimonios de los indios. Las razones para dudar de que existe matrimonio verdadero entre los indios son especialmente importantes: apenas se mantiene la vida conyugal entre los americanos por la facilidad con que dejan a la primera mujer y toman otra; no respetan la unidad del matrimonio, y mantienen varias mujeres a la vez. Además, difícilmente se puede saber si entre ellos existió consentimiento ${ }^{18}$.

El Speculum coniugiorum, texto en que se basa este trabajo, fue publicado por primera vez en 1556 en México. Para esta investigación hemos usado la versión complutense de 1572, recogida en la edición bilingüe de Luciano Barp, publicada por la Universidad La Salle de México. El Speculum coniugiorum tiene el propósito de confirmar que los indios son seres racionales, que entre ellos hay verdaderos matrimonios, que son animales políticos y que viven según los principios del derecho natural. En el Speculum, Alonso estudia el matrimonio de los indios combinando la doctrina escolástica con las costumbres esponsales de los pueblos americanos, que conoció directamente ${ }^{19}$. Éste no es un manual teórico sobre el matrimonio, sino una exposición de la praxis matrimonial de los indios a la luz del derecho natural. Es un texto de defensa de la naturalidad y multiculturalidad del matrimonio, claro en los razonamientos y escrito en un lenguaje sencillo ${ }^{20}$ (que parte de una lectura respetuosa de las costumbres esponsales de los americanos, las cuales compara con las ceremonias matrimoniales de los antiguos pueblos de Europa y Asia Menor $\left.{ }^{21}\right)$.

\section{EL DERECHO O LEY NATURAL}

En base a la definición tomista de la ley natural como luz de la razón que nos permite distinguir el bien del mal, Alonso desarrolla su exposición acerca del conocimiento moral y del matrimonio de los indios. Sostiene que la ley natural es

17 VeracruZ, Alonso de, Speculum coniugiorum (México DF, Universidad de La Salle, 2009-2013), I, a. 1, p. 67.

18 Tejero, Eloy, La primera valoración doctrinal del matrimonio de indios en Nueva España, en SARANYANA, Josep-Ignasi, et al. (eds.), Evangelización y teología en América (siglo XVI) (Pamplona, Eunsa, 1990), 2, p. 1295.

19 Goti, Juan, El 'Speculum coniugiorum' de Alonso de Veracruz y la inculturación del matrimonio canónico en México, en Ius canonicum, 39 (1999), 1, p. 621. Cuando el agustino prepara su obra sobre el matrimonio cuenta con una experiencia de treinta años viviendo con comunidades indígenas, especialmente de la zona de Michoacán. Conoce la lengua de los indios, ha participado en sus ritos y celebraciones y ha mantenido un diálogo fluido con parejas de indios, sabios del pueblo y sacerdotes del culto de los americanos. Veracruz, Alonso de, Speculum, cit. (n. 17), I, a. 43, p. 553; II, a. 2, p. 13.

${ }^{20} \mathrm{Y}$ así, "fue de suma utilidad práctica a todos los religiosos, que tropezaban con graves dificultades para resolver los intrincados casos que a cada paso se ofrecían en las cuestiones relativas al matrimonio de los indios”. García ICAZBALCETA, Joaquín, Bibliografía mexicana del siglo XVI (México DF, FCE, 1954), p. 145.

${ }^{21}$ Veracruz, Alonso de, Speculum, cit. (n. 17), II, a. 3, pp. 115 ss. 
un juicio práctico de la razón impreso por Dios en la mente de los hombres, "por el cual [uno] es dirigido para actuar en sus propias operaciones, ya sea que le competan por la naturaleza del género, en cuanto que es animal, como comer y engendrar, ya sea en cuanto que es hombre, como razonar, leer o algo similar" 22.

Toda la ley natural se resume en el primer principio de la razón práctica. Para la doctrina escolástica, que Veracruz suscribe, la ley natural es principio de ordenación de los actos humanos. Dirige al hombre hacia el bien moral, justamente lo que manda el primer principio práctico: "todo bien debe ser conseguido y todo mal debe ser evitado". Este principio, que se funda en la idea de que la naturaleza tiende al bien de cualquier ente ${ }^{23}$, es la raíz y fuente de la que manan todas las normas morales, aunque no es una premisa para los razonamientos (las normas morales, primarias o derivadas, incluso las normas positivas, se pueden entender como una modulación del principio "hay que hacer el bien y hay que evitar el mal").

En la relección De decimis Alonso se refiere al carácter suprapositivo del derecho natural ${ }^{24}$. Este derecho, dice, pertenece a la razón natural ${ }^{25}$, y sus preceptos son anteriores a la ley escrita ${ }^{26}$. Es un orden de justicia que sólo es accesible a la creatura racional, y que, como se indica en Speculum, sigue la inclinación de la naturaleza. Una idea semejante se defiende en De dominio infidelium et iusto bello: la razón natural dicta ciertas normas, como que "hay que vivir según la virtud"27, preceptos que se fundan en una suerte de equidad natural ${ }^{28}$.

La relación entre inclinaciones naturales y preceptos es una cuestión central en la teoría de la ley natural: aquellas cosas hacia las que el hombre tiene una inclinación natural, la razón las aprehende como buenas. Es decir, las cosas hacia las que el hombre siente connaturalidad se perciben como bienes humanos. Al contrario, aquellas cosas que el hombre rehúye se perciben como malas e injustas en su esencia ${ }^{29}$. En esto la exposición de Alonso no se aleja en lo más mínimo de la tesis de santo Tomás, que defiende la misma doctrina en la q. 94 a. 2 de la I-II de la Summa theologiae. Ahora bien, que el agustino sea fiel a santo Tomás no significa que no siga también a otros autores. Los escolásticos de formación salmantina, como Alonso, son tomistas abiertos, esto es, siguen a santo Tomás y lo presentan como un modelo para hacer teología, incluso lo citan más que a otros autores, pero toman elementos de otras tradiciones filosóficas para completar su pensamiento $^{30}$. Por eso, siguen también a Escoto, Egidio, Gerson, Cayetano, etc. En particular, Alonso sigue la doctrina de Escoto sobre la ley natural. La razón es simple: "Escoto es el autor que sirvió de puente entre el desarrollo de la ley natural

${ }^{22}$ Ibíd., II, a. 6, p. 135.

${ }^{23}$ Ibíd., II, a. 6, p. 139.

${ }^{24}$ Veracruz, Alonso de, De decimis. Sobre los diezmos (México DF, Organización de los Agustinos de Latinoamérica, 1994), $\$ 75$.

${ }^{25}$ Ibíd., $\$ \$ 903-914$. Donde se afirma que hay cosas que son clarísimas por la luz natural (\$ 909).

${ }^{26}$ Ibíd., $\$ 79$.

${ }^{27}$ Veracruz, Alonso de, De dominio infidelium, cit. (n. 16), $\$ 57$.

${ }^{28}$ Ibíd., $\$ \$ 64$ y 302.

${ }^{29}$ VeracruZ, Alonso de, Speculum, cit. (n. 17), II, a. 7, p. 155.

${ }^{30}$ Belda Plans, Juan, cit. (n. 10), pp. 220-229. 
medieval y la paulatina autonomía de la conciencia; de él bebieron conciliaristas moderados como Juan Gerson y otros más radicales como Almayn, Biel, Nicolás de Cusa, todos estos citados en las obras de fray Alonso"31.

Alonso asume una concepción trimembre del derecho natural. Distingue un momento intelectual y uno estrictamente racional en el conocimiento práctico. Habla, así, de un derecho natural que es evidente, que todos conocen sin error, y de un derecho natural demostrable, que exige el esfuerzo de la razón. En este sentido, escribe: "lo que es por derecho natural lo es de modo triple. El primero se funda en los principios fundamentales del derecho natural, como aquello de que lo que no quieres para ti no lo hagas a los demás', y aquello de que 'hay que huir del mal y buscar el bien'. El segundo modo de derecho natural consiste en aquello que se deriva inmediatamente de estos principios, como las conclusiones de los principios, como los preceptos del decálogo, por lo menos los de la segunda tabla [...] El tercer modo para que algo se diga que es derecho natural, consiste en que se derive ciertamente de la ley natural, si no inmediatamente, si muy mediatamente, y no está determinado por la ley natural, sino aprobado por la ley humana o la costumbre. Asi por ejemplo, la ley natural pide que al malhechor se le aplique una pena, pero no que un ladrón, que es malhechor, sea azotado, o condenado al destierro o privado de sus derechos, sino que es la ley humana lo que la determina"32.

Esta explicación de los niveles del derecho natural es un poco diferente de la que ofrecen otros autores de la Escolástica salmantina. Vitoria, Soto, Molina, Suárez, Vázquez, etc., aunque distinguen tres grupos de preceptos en la ley natural, no están diciendo exactamente lo mismo que Veracruz. Alonso matiza y cambia la naturaleza del derecho natural terciario. Lo identifica con el conjunto de preceptos que se imponen a partir de la ley humana, lo cual, por ejemplo, en la tesis de Soto, no se puede considerar como de derecho natural. Pero esto no tiene importancia. Veracruz no es un teórico de la ley natural. Es un "ideólogo práctico" ${ }^{33}$. No pretende construir una teoría completa sobre la ley natural como orden normativo. Él busca resolver los problemas de los indios. De ahí que matice, reelabore, cambie de opinión, cite otras fuentes, etc.

No todas las normas que se deducen de la ley natural son también leyes naturales. Así se lee en Speculum II, 25. Si así fuera, todos los principios de justicia, incluso los preceptos de derecho positivo, serían morales, ya que todas las clases de leyes se derivan, en cierta forma, de la razón natural. Ahora bien, las leyes que tratan sobre materias indiferentes no son parte de lo justo natural sino de lo justo legal, como que se ofrezca una cabra y no dos ovejas en sacrificio ${ }^{34}$. Por ende,

${ }^{31}$ Aspe, Virginia, Del viejo al nuevo mundo. El tránsito de la noción de dominio y derecho natural de Francisco de Vitoria a Alonso de la Veracruz, en Revista Española de Filosofía Medieval, 17 (2010), p. 145.

32 Veracruz, Alonso de, De decimis, cit. (n. 24), $\$ 53$.

33 La expresión es de Miguel Anxo Pena. Pena González, Miguel Anxo, Fray Alonso de la Veracruz: un antecedente de la independencia americana, en ESQUIVEL, Héctor (compilador), Pensamiento novohispano (Toluca, Universidad Autónoma del Estado de México, 2011), p. 41.

${ }^{34}$ Veracruz, Alonso de, Speculum, cit. (n. 17), II, a. 25, p. 357. 
sólo son normas morales o naturales aquellas que se deducen directamente de los primeros principios de la ley natural ${ }^{35}$.

Aunque Alonso habla de distintos niveles de preceptos en el derecho natural, lo cierto es que, por lo menos en Speculum, el autor parece reducir el derecho natural a los principios primeros o per se nota. En este sentido, es común encontrarse con fórmulas como "esto es asi porque lo dicta la naturaleza", expresión que, por lo general, se debe entender como referida a los principios primarios. Quizá esto se deba a que no existe desacuerdo respecto del derecho natural primario. “Todos lo conocen sin esfuerzo". Es un derecho firme, cierto, y es el principio de todo razonamiento posterior. Siguiendo la lógica del Elenchorum, se podría decir que toda la ley natural existe en estos principios, pues a partir de los primeros principios se causan todas las demostraciones ${ }^{36}$.

Tales principios son inmediatos y necesarios ${ }^{37}$. Son comunes, inmutables, evidentes $^{38}$. Que sean evidentes no significa que sean innatos. Se conocen a partir de la experiencia y gracias a la iluminación del intelecto agente (por eso, anota Alonso, "el entendimiento agente abstrae del fantasma las especies inteligibles" ${ }^{39}$ ). Dado que todos los hombres tienen la misma naturaleza, se sigue que estos principios son iguales para todos, en todos los tiempos y en todos los lugares ${ }^{40}$.

A diferencia de los principios comunes, los principios derivados admiten cambio y no son los mismos en todas partes. De ahí que, en ocasiones, Alonso afirme que "la ley natural es variable y no es la misma en todas las naciones" ${ }^{41}$. Estos principios no son evidentes para todos sino sólo para aquellos que no ignoran su relación con los preceptos per se nota. Igualmente, los principios secundarios " $n o$ tienen de por si fuerza alguna para obligar" ${ }^{42}$. Esas normas obligan sólo en la medida en que están declaradas por una ley humana o divina, o por una costumbre que tiene fuerza de ley.

La diversidad de formalidades para el matrimonio es una consecuencia del carácter mutable de los principios derivados. Veracruz señala que "se juzga de muchas maneras acerca de aquellas cosas que no son determinadas por la naturaleza"43. Y como las normas sobre el matrimonio no están todas determinadas por naturaleza, en el sentido de que no pertenecen al derecho natural evidente, los cultos, las formas, los impedimentos, los requisitos, todo puede cambiar y ser materia de discusión. Lo único que no puede cambiar es lo que el derecho natural prohíbe

35 Ibíd., II, a. 25, p. 359.

36 VeracruZ, Alonso de, Elenchorum. Libro de los elencos sofisticos (México DF, Unam, 1989), c. 1, p. 3.

37 Ibíd.

38 Veracruz, Alonso de, Speculum, cit. (n. 17), II, a. 7, p. 155.

39 Veracruz, Alonso de, De anima. Investigación filosófico-natural. Los libros del alma (México DF, Universitaria, 1942), p. 85.

${ }^{40}$ Veracruz, Alonso de, Speculum, cit. (n. 17), II, a. 7, p. 161. Escribe el autor: "en todas las gentes existe la misma rectitud acerca de los primeros principios, sin embargo, no es necesario que esto sea verdadero acerca de todas las conclusiones que se deducen de los primeros principios".

41 Ibíd., II, a. 7, p. 157.

42 Ibíd., II, a. 27, p. 395.

43 Ibíd., II, a. 7, p. 157. 
de forma absoluta ${ }^{44}$, o, lo que es lo mismo, lo que la ley natural designa como contrario al fin del hombre ${ }^{45}$.

\section{El MATRIMONIO COMO REALIDAD NATURAL}

Inspirado en Aristóteles, Alonso dice que el matrimonio es una institución $\mathrm{n}$ a t u ra l. El agustino llama $\mathrm{n}$ a $\mathrm{t} \mathrm{u} \mathrm{ral}$ a lo que es $\mathrm{d}$ i c t a d o por la naturale$\mathrm{za}^{46}$. Ahora bien, la naturalidad de las cosas se comprende a partir del fin, y así se entiende que la naturaleza haya dado a los hombres ojos para ver y para cuidarse de los peligros. "Por ello es necesario que los ojos estén puestos en la cabeza y no en los pies, puesto que el hombre no podría cómodamente conseguir el fin premeditado si estuvieran en los pies" ${ }^{\prime 7}$.

Siendo Dios el creador de todo cuanto es natural, no cabe duda de que también el matrimonio, al ser una realidad natural, es creación divina. El razonamiento de Veracruz es el que sigue: "afirmamos que el matrimonio fue instituido por Dios mismo, el formador de todas las cosas, ciertamente como deber, en aquel paraíso de delicias, antes del pecado de los primeros seres creados, cuando a Adán le fue dada una ayuda semejante a él mismo. Del cual, cuando estaba adormecido, fue extraida y conformada Eva, para que hueso de sus huesos y carne de su carne, los dos fueran una sola carne" 48 .

El matrimonio es una realidad ordenada a que las sociedades continúen en el tiempo. Alonso lo define como la unión del hombre y de la mujer ${ }^{49}$, lo cual, expone, "se prueba a partir de Aristóteles, quien sostiene que el hombre es, por naturaleza, más conyugal que político" ${ }^{50}$. La referencia a Aristóteles es inexacta, pues, en realidad, este autor diría lo contrario, al menos en el sentido relevante de n a t u r a l.

El matrimonio no pertenece al ámbito de lo natural-físico, como la ley de la gravedad, sino al ámbito de lo natural-libre, como el resto de los actos morales. De ahí que el agustino señale que es causado por el libre acuerdo de las partes ${ }^{51}$. El sentido de n a t u r a l que interesa a Veracruz es el de "aquello a lo que la naturaleza inclina". Considerado de este modo, "el matrimonio se dice natural o de derecho natural en cuanto que el hombre por naturaleza se inclina hacia el matrimonio, aunque su perfección dependa del libre albedrio, mediante el consentimiento" ${ }^{52}$.

Si el matrimonio es una realidad natural, será posible encontrarlo aun entre los

${ }^{44}$ Veracruz, Alonso de, De dominio infidelium, cit. (n. 16), $\$ 915$.

${ }^{45}$ Sobre este punto: MEDinA, Yail, Ley natural y matrimonio en el Espejo de los cónyuges de Alonso de la Veracruz, en Velasco, Ambrosio (ed.), Fray Alonso de la Veracruz: universitario, humanista, científico y republicano (México DF, Unam, 2009), p. 138.

${ }^{46}$ Veracruz, Alonso de, De iusto bello contra indios, (Madrid, CSIC, 1997), q. 4, p. 185.

47 Veracruz, Alonso de, Speculum, cit. (n. 17), I, a. 1, p. 57.

${ }^{48}$ Ibíd., I, a. 1, p. 55.

${ }^{49}$ Ibíd., I, a. 1, p. 57.

${ }^{50}$ Ibíd., I, a. 1, p. 57 (texto ligeramente modificado).

${ }^{51}$ Ibíd., I, a. 1, p. 59.

52 Ibíd., I, a. 1, p. 59. Prosigue: "aunque el hombre sea movido hacia el matrimonio por el libre albedrío, sin embargo, es natural, dado que hay una inclinación hacia aquél, aunque se complemente mediante la voluntad". 
pueblos no cristianos, a pesar de que su estructura y formalidades sean distintas. En efecto, "si es algo natural (dado que las realidades naturales no fueron abolidas por el pecado aunque hayan permanecido lesionadas) no negaremos que el matrimonio existe también entre los pecadores. Asimismo, dado que los infieles mantienen integras las cualidades naturales, aunque oscurecidas, será necesario afirmar, total y constantemente, que también entre los infieles hay matrimonio" 53 .

Puesto que lo natural depende del fin, es necesario aclarar el fin que tiene el pacto esponsal. Veracruz entiende que el fin del matrimonio es doble: por una parte, la propagación y continuación de la especie y, por otra parte, el mutuo obsequio de los cónyuges (también habla de la comunicación en las obras ${ }^{54}$ ).

La procreación es un fin que es de bien común ${ }^{55}$, y no se puede identificar con la simple unión física de los cónyuges, porque eso es propio de los brutos, donde no hay matrimonio. En el hombre, al contrario, está también la inclinación al cuidado y educación de los hijos (y "la naturaleza intenta más la educación y la perfección de la prole que la procreación" ${ }^{6}$ ). A este respecto, señala el autor: "para esta primera finalidad no debe haber la relación de hombre y mujer solamente en el tiempo de la unión carnal, sino durante todo el tiempo de la educación de la prole. En efecto, la naturaleza tiende a la educación y a la perfección de los engendrados, más que a la generación misma. En efecto: aquello para lo cual algo es así, aquello mismo es más perfecto. Por lo tanto, si (la naturaleza) quiere la generación por razón de la prole, quiere más la prole. Asi como la naturaleza inclina al macho y a la hembra hacia la unión, para engendrar a un ser similar a si mismos, los inclina también a relacionarse de un cierto modo, para que puedan educar bien a los nacidos. Y esta relación es llamada matrimonio" 57.

En cuanto a la ayuda mutua, dice Veracruz que los esposos deben dedicarse de modo recíproco a los asuntos domésticos ${ }^{58}$. En su opinión, por inclinación natural, "en las obras que se refieren a la conservación de la vida, algunas son obras que se hacen convenientemente por los varones y otras por las mujeres" $"$. De ahí que la asociación de los esposos y la comunicación en las obras sean de derecho natural.

La argumentación de Alonso continúa con la afirmación de que lo natural es igual en todas partes. El problema es que el matrimonio está sometido a la diversidad de los tiempos, "ya que según las diversas condiciones de los hombres, se contrae de diversa manera, y diversos son los ritos y las ceremonias para contraer matrimonio" 60 . La causa de esto es que la naturaleza del hombre no es inmóvil,

53 Ibíd., I, a. 1, p. 57.

${ }^{54}$ Ibíd., II, a. 6, p. 145.

55 Ibíd., I, a. 1, p. 61.

56 Ibíd., I, a. 1, p. 63.

${ }^{57}$ Ibíd., I, a. 1, p. 63. Para Alonso, que los hijos no sean criados por ambos padres es un mal grave. Por eso, señala, la indisolubilidad del matrimonio, como condición para una adecuada crianza de los hijos, es de la esencia del pacto esponsal. Veracruz, Alonso de, Speculum, cit. (n. 17), I, a. 1, p. 67.

58 Ibíd., I, a. 1, p. 65.

59 Ibíd., I, a. 1, p. 65.

${ }^{60}$ Ibíd., I, a. 1, p. 65. 
como la naturaleza divina. Los hombres están sometidos al tiempo y la cultura y las tradiciones cambian según la geografía, creencias, lengua, etc.

El matrimonio, piensa Veracruz, no está protegido por los principios primarios de la ley natural. Tal es la razón por la que puede cambiar. La mutabilidad del matrimonio, al menos en los aspectos que no son esenciales, depende de la mutabilidad de los preceptos que lo regulan, y éstos, como se ha dicho, son preceptos derivados y no evidentes ${ }^{61}$.

Lo que cambia en el matrimonio es lo circunstancial. Lo que pertenece a la esencia del pacto esponsal no puede variar. Lo esencial en el matrimonio es el consentimiento libre de las partes. Hay matrimonio cuando la voluntad no se ve coartada por la fuerza, o por el miedo, o por el error. Todo lo demás está sometido a la convención. Las formas, los requisitos, incluso los impedimentos, casi todo ello pertenece al derecho positivo.

Cuando escribe el Speculum, Alonso se propone responder a la pregunta por la legitimidad o ilegitimidad de los acuerdos esponsales que ha visto en México y que existen en otras regiones de América, como Perú y Nicaragua ${ }^{62}$. En general, y porque intenta subrayar la racionalidad de los indios, Alonso va a poner de relieve que los matrimonios celebrados en América son válidos y que, por lo mismo, no se pueden romper. La indisolubilidad del pacto existe aun cuando la práctica de algunos indios sea el divorcio. Luego, si bien, en la práctica, se da el repudio, el contrato celebrado válidamente sigue existiendo. El divorcio sólo es una ficción legal, que existe porque, en los indios, opera una suerte de conciencia invenciblemente errónea ${ }^{63}$. Además, no se puede presumir que los americanos querían ya la ruptura del vínculo al momento de contraer.

Aunque el matrimonio es una unión entre un hombre y una mujer, expone Veracruz que no es la unión entre cualquier hombre y cualquier mujer. La razón natural prohíbe el matrimonio entre padres e hijos. El hombre, a diferencia de los animales, puede identificar la razón de maldad o injustica que hay en una unión como esa: "no debe haber unión con cualquier mujer, sino que de la unión deben ser excluidas algunas con las cuales (por razón de reverencia) la naturaleza

${ }^{61}$ Escribe Alonso: "Por ello en aquellas cosas que se deducen de estos principios (como es el vínculo indisoluble del matrimonio) puede haber alguna variación, según los diversos tiempos, o bien según las diferentes naciones, lo cual no puede ocurrir en los mismos primeros principios que son evidentes por sí mismos. Por cierto, que esa unión indisoluble sea necesaria para la generación de la prole, no es algo tan evidente, sin embargo, se deduce de principios evidentes. En efecto, si a nadie se debe hacer el mal y, por el hecho de que los padres no están vinculados mutuamente, se sigue un mal para la prole, ya que no es educada debidamente, como se ha dicho, entonces la indisolubilidad del matrimonio es necesaria. Por esto, no es inconveniente que, según los diversos estados y condiciones de la gente, el matrimonio varie, no sólo en cuanto a las ceremonias (como se dice en Extra, De sponsalibus, c. De Francia) sino también en cuanto a lo sustancial, como que alguna gente ponga en el matrimonio la pluralidad [de esposas], y otra la unicidad, y algunos admitan la indisolubilidad; mientras que otros, el repudio". Veracruz, Alonso de, Speculum, cit. (n. 17), I, a. 1, p. 67.

62 Ibíd., II, a. 2, p. 93.

${ }^{63} \mathrm{La}$ diversidad de ritos no afectaba a la validez del acuerdo esponsal. Habiendo consentimiento libre entre personas hábiles existía verdadero matrimonio. GoTI, Juan, cit. (n. 19), p. 628. 
no soporta unirse" "A4. Ahora bien, "los ganados, dado que ignoran tal relación, no excluyen hembra alguna de la unión, aunque algunos, en los cuales hay conocimiento de los padres, se abstienen de la unión con ellos. A propósito, Aristóteles relata que un caballo, apareado por medio de engaño con su madre, cuando se dio cuenta de dicha situación, se precipitó [se arrojó al precipicio], como si hubiese pecado en contra de la ley natural"65.Y añade: "entre los habitantes del Nuevo Mundo no se ha encontrado unión alguna entre padres e hijos, mientras que no hay limites en cuanto a las otras uniones. En efecto, vemos que ellos no aborrecen los concúbitos entre hermanos y demás consanguíneos, sin embargo, hasta ahora jamás he oído que el hijo se haya unido con su madre, no solamente en matrimonio, sino tampoco en algún otro concúbito incestuoso. Y tampoco que el padre se haya unido con su hija"66.

\section{El matrimonio en la exposición de VeracruZ}

\section{El consentimiento como esencia del matrimonio}

El matrimonio es un contrato de vida entre un hombre y una mujer que se unen "para engendrar a un ser similar a sí mismos" ${ }^{67}$. La esencia del matrimonio es el acuerdo o consentimiento; y el consentimiento es "la aplicación de la voluntad a algo que debe ser efectuado" 68 " "la sentencia final del intelecto y de la voluntad"69.

El matrimonio involucra la entrega mutua de los cónyuges. Como esa entrega es completa, los cónyuges deben manifestar inequívocamente su intención de vivir en matrimonio. De esta manera, se afirma que éste es causado por la voluntad, mediante el libre consentimiento ${ }^{70}$.

Consentir es un fenómeno exclusivamente humano. Es el resultado de un acto conjunto del conocer y del querer. Según indica Alonso, en el caso del matrimonio el consentimiento debe prestarse con relación a una persona determinada, y con clara conciencia de entender los fines de la procreación y la comunicación de las obras ${ }^{71}$.

Sobre la manera como se ha de prestar el consentimiento, Alonso enseña que debe ser explícito o, por lo menos, implícito pero inequívoco, o sea, eficiente para realizar "aquel contrato que hacen aquellos que quieren ser marido y esposa"72. Este acuerdo de voluntades es lo único que se requiere para causar el matrimonio (el consentimiento es el único requisito de necesidad $)^{73}$. Por esta razón, aun los que no han reflexionado largamente sobre el pacto esponsal pueden estar realmente casados $^{74}$.

${ }^{64}$ Veracruz, Alonso de, Speculum, cit. (n. 17), I, a. 1, p. 61.

${ }^{65}$ Ibíd., I, a. 1, p. 61.

${ }^{66}$ Ibíd., II, a. 22, p. 329.

${ }^{67}$ Ibíd., I, a. 1, p. 63.

${ }^{68}$ Ibíd., I, a. 2, p. 77.

${ }^{69}$ Ibíd., I, a. 2, p. 77

${ }^{70}$ Ibíd., I, a. 1, p. 59

${ }^{71}$ Ibíd., I, a. 2, p. 79

72 Ibíd., I, a. 2, p. 83.

${ }^{73}$ Ibíd., I, a. 2, p. 81.

${ }^{74}$ Ibíd., I, a. 2, p. 83. 
Alonso dedica el a. 3 de la primera parte de su Speculum a la pregunta de si es necesario que el consentimiento sea expresado con palabras, con señas o con acciones. Parte de la afirmación de que el consentimiento interno, si bien es indispensable, no es suficiente para generar el vínculo esponsal. Se exige su manifestación externa. Así, Veracruz afirma que las palabras son necesarias para expresar el consentimiento. Pero si los contrayentes no pueden hablar o no es costumbre hacerlo durante el rito, estima que bastan los signos que expresan la voluntad esponsal ${ }^{75}$. En cualquier caso, es necesaria la manifestación exterior del consentimiento. Si bastara la sola voluntad interna de las partes, ésta podría ser revocada incluso antes de que el otro aceptara ${ }^{76}$.

Respecto del problema del consentimiento en los matrimonios de indios, señala Alonso: "Cuando no ha precedido signo alguno que exprese el consentimiento y no precedió palabra alguna ni alguna otra cosa acerca del matrimonio, tal modo de unión no hace matrimonio alguno, ni siquiera presunto, aunque permanezcan juntos por mil años como marido y mujer, o tengan la intención de querer unirse matrimonialmente, sea que piensen en nada, sea que solamente piensen en el pecado"77.

A continuación Alonso se pregunta si la manifestación exterior de la voluntad puede hacerse con palabras de presente o de futuro. El agustino recuerda que los términos son expresiones de los conceptos del alma, y que las palabras " $n$ o significan por su naturaleza, sino ad placitum por imposición de los hombres [...] Luego deben ser tomadas en aquel sentido según el cual son tomadas comúnmente por aquellos que hablan"78. Por lo mismo, así como en cualquier contrato se entiende que es celebrado sólo cuando se usan palabras de presente, sin palabras de presente no hay verdadero matrimonio ${ }^{79}$.

Alonso se pregunta si es suficiente para la validez del matrimonio que uno solo de los contrayentes exprese su voluntad, mientras el otro no lo contradiga. Las distintas formas en que esto puede ocurrir son: que una de las partes consienta y la otra no disienta ni consienta, o que la voluntad de la mujer sea prestada por sus padres u otra persona ${ }^{80}$. La tesis del autor es que la voluntad esponsal debe ser expresada por ambos contrayentes, por sí o por medio de terceros ${ }^{81}$. Con todo, si una de las partes expresa su voluntad con palabras de presente y la otra no dice nada, y dado el caso de que la unión esponsal se consume, Alonso afirma que se presume el matrimonio (pues, indica, "no puede existir algún otro signo más expresivo para el consentimiento que la entrega misma, mediante la cual, entregándose el varón, ella recibe la potestad sobre el mismo") ${ }^{82}$.

Por último, Veracruz postula que si una de las partes expresa su voluntad y la

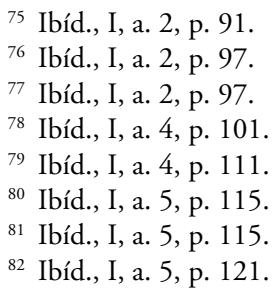


otra no, pero lo hacen sus padres, ese pacto esponsal se tendrá por válido ${ }^{83}$. También será válido el matrimonio que se realiza por orden de la autoridad, siempre que las partes no se opongan ni exterior ni interiormente.

\section{La celebración}

Para Alonso, el modo de la celebración es accidental ${ }^{84}$. Mientras la obligación mutua de los contrayentes es invariable, la forma de contraer el pacto cambia según las circunstancias. Por ejemplo, Veracruz expone que en América los modos de casarse eran distintos según las provincias y el tipo de personas ${ }^{85}$, si bien siempre se trataba de matrimonios reales: "entre los infieles del Nuevo Mundo se daba un verdadero matrimonio, aunque tenian sus formas propias de contraerlo, porque consideraban el matrimonio como la unión natural de hombre y mujer. Pero hay que advertir que no eran de la misma forma en toda la provincia, ni aun en la misma ciudad, sino que eran varias, aunque esta variedad de celebraciones no modifica el matrimonio, siempre que los contrayentes entendieran que querian hacer una unión natural de hombre y mujer" $"$.

Lo ceremonial no cambia la naturaleza del pacto matrimonial cuando se conservan los elementos esenciales ${ }^{87}$. Es decir, siempre que estamos ante la unión de un hombre con una mujer que quieren vivir juntos y respetarse de por vida, buscando la procreación y educación de la prole y la comunicación en las obras, los ritos o diferencias cultuales no afectan ni alteran la voluntad esponsal ${ }^{88}$.

Alonso se sorprende de la diversidad de cultos y destaca el hecho de que los indios gocen de una riqueza cultural tan grande. La variedad de ritos y prácticas no lo inquietan, como sí inquietan a Sepúlveda y otros autores escolásticos del siglo XVI. El estudio de Alonso se centra, casi exclusivamente, en la región de Michoacán, donde las formas contraer eran particularmente diversas: por ejemplo, los matrimonios de indios nobles involucran a toda la familia, máxime a los padres de los contrayentes, si bien es celebrado libremente por ellos. Es el único rito en que participa activamente un sacerdote, que recibe los dones de las partes y atestigua el intercambio de los mismos por los contratantes. A este respecto, se lee en Speculum: "El mismo sacerdote entregaba los dones al esposo y a la esposa, y les decía: 'Quieran los dioses que vosotros os asociéis bien en la unidad, conservando mutuamente la fidelidad entre vosotros'. Los padres de los mismos jóvenes les decian: 'Ved que mutuamente os améis y mutuamente deis y recibáis dones. En esta unión, nada de vano será mezclado. Ninguno de vosotros se entregará a alguien en concúbito adulterino. Ved que nadie os mate por algún adulterio" $"$.

Entre los indios más pobres se celebraban ceremonias más sencillas. Los padres de los novios acordaban antes los términos del contrato. Luego los novios inter-

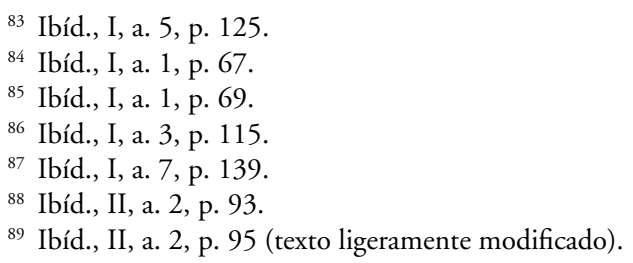


cambiaban sus dones y el padre de la novia la exhortaba a ser fiel. Antes de vivir juntos, durante algunos días seguidos, el hombre recogía leña para ser quemada en el templo, mientras la mujer barría la casa y la calle por donde llegaría el novio. Después que la mujer vestía al varón, quedaban desposados ${ }^{90}$.

Veracruz muestra también la forma de casarse en secreto. Sin que los padres o parientes supieran, una pareja se unía en matrimonio diciendo uno de los dos: "Tú me cultivarás el campo; yo te tejeré los vestidos; del mismo modo yo te cocinaré el pan y serviré otras cosas necesarias para la comida" . Aunque secretos, Veracruz considera que éstos eran verdaderos matrimonios, porque las partes se unían para la comunicación en las obras y porque luego de las palabras empezaban a vivir juntos ${ }^{92}$.

También existía la costumbre de que "alguien tomaba a una mujer como esposa hasta que la hija llegase a la edad de contraer matrimonio y, después, cuando la hija había llegado a tal edad, se unían sin otro consentimiento" ${ }^{93}$. Lo mismo ocurría entre hermanas: una se daba por esposa hasta que la otra llegara a la pubertad. Veracruz considera que habría verdadero matrimonio si la joven, a la edad de casarse, entendía que había sido dada como esposa y se unía "con afecto marital" a aquel que la había desposado ${ }^{94}$.

Alonso, en suma, teniendo presente que los hombres viven dentro de una cultura y que se desarrollan sobre la base de ciertas costumbres y prácticas sociales, se interesa por la vida esponsal de los indios, la que defiende y promueve a partir de las normas sobre el matrimonio natural, pese a que estas formas matrimoniales eran completamente distintas a las que se conocían en Europa. Con esto defiende a los pueblos del Nuevo Mundo y resalta su racionalidad y autodominio.

\section{El imPedimento DE PARENTESCO}

Como se ha dicho, para Alonso hay ciertas personas que no pueden casarse entre sí, porque la misma naturaleza lo prohíbe ${ }^{95}$. Para este autor, sólo hay matrimonio en las uniones que no se oponen a la naturaleza: "cuando ocurre una unión que se opone a la naturaleza, no hay matrimonio, dado que en su esencia el matrimonio implica la unión de un determinado varón con una determinada mujer" ${ }^{\prime \prime}$. Tal es el caso de los parientes consanguíneos en línea recta y segundo grado de línea colateral.

Antes de analizar este impedimento expondremos qué entiende Veracruz por parientes consanguíneos. Se trata de aquellos que descienden de manera próxima de un mismo tronco "por propagación carnal"'

\footnotetext{
90 Ibíd., II, a. 2, p. 97.

${ }^{91}$ Ibíd., II, a. 2, p. 97.

${ }_{92}$ Ibíd., II, a. 2, p. 97.

93 Ibíd., II, a. 2, p. 113.

94 Ibíd., II, a. 2, p. 113.

95 Ibíd., I, a. 1, p. 61.

${ }_{96}$ Ibíd., II, a. 22, p. 327.

${ }^{97}$ Ibíd., I, a. 43, p. 545.
} 
de sangre se da cierta unidad y semejanza que causa una amistad natural y que permanece entre los parientes consanguíneos más próximos ${ }^{98}$.

Para determinar el nivel de parentesco, el agustino explica los conceptos de línea y grado. La línea es el conjunto de personas que descienden de un mismo tronco. Se cuenta por línea ascendente o descendente o transversal. El grado es la distancia entre los parientes consanguíneos y se cuenta por generaciones.

Supuesto lo anterior, se oponen al derecho natural "la unión de padre e hija, o bien, de hijo y madre [...] por el hecho de que por naturaleza los hijos deben honor y sujeción a los padres. Y entre ellos no puede existir aquella igualdad que existe entre varón y mujer" 99 . Además, en las uniones de este tipo "no habría obediencia alguna [...] ya que la madre debería obedecer al hijo. Y esto repugna. Luego se sigue que tal unión entre consanguineos en linea recta se opone al derecho natural. Se sigue también que los infieles así unidos en tal grado, no deben ser tolerados después de la conversión. Nos enseñan esto los ejemplos de los animales, que, aunque carecen de la razón, sin embargo, tienen algún instinto natural para evitar tal unión, como [...] se dice de un elefante que, engañado mediante un artefacto, fue apareado con su madre $y$ después mató al artifice"100.

En contra de esta conclusión, dice Alonso, está el hecho de que, en Asiria, se dictó una ley en la que se permitía que las mujeres se casaran con sus hijos. Sin embargo, "que el hijo se case con su madre, o el padre con su hija, se opone a los primeros preceptos del derecho natural, entre los cuales se encuentran el honor y la reverencia debida a los padres y a los superiores"101 (es de advertir que, según santo Tomás, el precepto de honrar a los padres, que pertenece al decálogo, es principio secundario o derivado).

Los matrimonios celebrados en contravención del derecho natural son nulos de nulidad absoluta. Por tanto, los hombres y mujeres unidos en los grados prohibidos por la ley natural no conforman verdaderos matrimonios ${ }^{102}$. Ninguna ley positiva puede hacer lícito el acto contrario al derecho natural. Por eso, ninguna ley humana puede hacer que el matrimonio entre padres e hijos sea lícito. En realidad, una norma como ésta ni siquiera debiera llamarse ley, "pues una ley en contra del derecho natural carece de razón y asi no es una ley"103.

En opinión del agustino, el impedimento de consanguinidad en la línea recta tiene un término y un límite: no se extiende al infinito ${ }^{104}$. Con esta idea, Alonso asume la doctrina de santo Tomás, san Buenaventura y Alejandro de Hales, los cuales, al igual que respecto de la línea colateral, plantean que ese impedimento tiene un fin. Aquí se presenta un punto interesante en relación con la normativa canónica actual. El Código de Derecho Canónico señala que la prohibición de parentesco se extiende a toda la línea recta y a la línea colateral hasta el segundo

\footnotetext{
98 Ibíd., I, a. 43, p. 549.

99 Ibíd., II, a. 22, p. 327.

${ }^{100}$ Ibíd., II, a. 22, p. 329.

101 Ibíd., II, a. 22, p. 333.

${ }^{102}$ Ibíd., II, a. 22, p. 327.

103 Ibíd., II, a. 22, p. 331.

${ }^{104}$ Ibíd., I, a. 43, p. 549.
} 
grado $^{105}$. La norma en cuestión tiene por objetivo proteger la dignidad de la persona y el carácter específico de la cercanía familiar que proporciona, por vía biológi$\mathrm{ca}$, la relación entre parientes ${ }^{106}$. En otras palabras, se intenta que las relaciones familiares no se desvirtúen por la esperanza de una relación conyugal ${ }^{107}$. Y así, la doctrina canónica mayoritaria entiende que es probable que el derecho natural incluya toda la línea recta y el segundo grado de línea colateral ${ }^{108}$. Justamente, lo que niega el agustino español.

Veracruz insiste en que no todos los grados de parentesco por consanguinidad están prohibidos por la ley natural. Se dice que algo es prohibido por la ley natural cuando impide conseguir el fin al que el hombre está inclinado por naturaleza. Y el fin del pacto esponsal se cumple igualmente en ciertas uniones entre parientes por consanguinidad, como en las uniones entre hermanos ${ }^{109}$, o en el matrimonio con la tía paterna o con la tía materna. Para Alonso, entonces, sólo están prohibidas las uniones entre parientes directos o inmediatos ${ }^{110}$ (en el mismo sentido: sólo se prohíben por ley natural los actos intrínsecamente malos. Y no todos los grados de parentesco se refieren a actos malos per se).

Con respecto al matrimonio entre hermanos, Alonso afirma que por derecho natural se prohíbe ${ }^{111}$. Reafirma esto con su experiencia de haber vivido treinta años entre los pueblos originarios de México y de haber visto que la unión conyugal entre hermanos se consideraba como algo vicioso ${ }^{112}$. Sin embargo, considera que la prohibición del matrimonio entre hermanos no es propia del derecho natural primario, sino sólo del derecho natural secundario. Ya hemos señalado que, para Veracruz, los preceptos secundarios no obligan por sí, sino sólo en la medida en que están declarados por una norma de derecho humano o divino, o por una costumbre que les otorga fuerza obligatoria. En este contexto, anota el autor:

105 Código de Derecho Canónico De 1983, canon 1091: “\$ 1. En línea recta de consanguinidad, es nulo el matrimonio entre todos los ascendientes y descendientes, tanto legítimos como naturales. $\$ 2$. En línea colateral, es nulo hasta el cuarto grado inclusive. $\$ 3$. El impedimento de consanguinidad no se multiplica. $\$ 4$. Nunca debe permitirse el matrimonio cuando subsiste alguna duda sobre si las partes son consanguineas en algún grado de linea recta o en segundo grado de linea colateral'.

106 Bañares, Juan Ignacio, Comentario al canon 1091, en MarzoA, Ángel, Miras, Jorge y Rodríguez-OCAÑA, Rafael (coordinadores), Comentario Exegético al Código de Derecho Canónico (Pamplona, Eunsa, 2002), III/2, pp. 1200-1201.

107 BocCAFOLA, Kenneth, Gli impedimenti relativi ai vincoli etico-giuridici tra le persone: afinitas, consanguinitas, publica honestas, cognatio legalis, en BONNET, Piero Antonio, y Gullo, Carlo, Diritto matrimoniale canonico (Città del Vaticano, Libreria Editrice Vaticana, 2002), 1, p. 557.

108 AzNar GIL, Federico, El nuevo Derecho matrimonial canónico (Salamanca, Universidad Pontificia de Salamanca, 1984), p. 224.

109 Alonso indica que el matrimonio entre hermanos no está prohibido por el derecho natural, ya que no está prohibido en todos los lugares, como sí lo estaría si fuera una norma iusnatural -aquí se ve cómo para Alonso el derecho natural parece quedar reducido a los principios primarios, pues sólo ellos son universalísimos-. VeracruZ, Alonso de, Speculum, cit. (n. 17), II, a. 27, p. 337.

${ }^{110}$ Ibíd., II, a. 27, p. 399.

111 Ibíd., I, a. 43, p. 553.

112 Ibíd., I, a. 43, p. 553. 
"Supuestas estas cosas, hay que decir lo siguiente: Aunque sea cierto que la unión de hermanos en el primer grado de la linea transversal está prohibida por el derecho natural secundario, sin embargo, tal derecho natural puede ser cambiado por otro además que por Dios, sin un milagro. La razón es porque tal derecho natural no obliga, si no fue constituido por una ley divina o humana, o por una costumbre; sin embargo, aquel que editó una ley acerca de aquello y, a causa de ella vinculó a tal derecho, podrá también desobligar quitando la ley o dispensando en la ley"113.

Además, si el matrimonio entre hermanos fuera directamente contrario a la naturaleza del hombre, "Dios habría creado a dos o a tres varones y a otras tantas mujeres que, una vez unidos, podrian procrear y asi no se unirian entre si los hermanos, sino otros consanguineos. Por tanto, dado que creó a un solo varón y a una sola mujer y permitió que se uniesen los hijos de ellos, se sigue que esto no fue malo de por si y que no fue de los primeros preceptos del derecho natural' 114 .

A partir del principio paulino según el cual "muchas cosas son lícitas, pero no todas convienen", Alonso da un paso hacia la justificación del impedimento de consanguinidad, que no pertenece al derecho natural sino al derecho positivo: "que tal unión es algo malo se declara mediante una ley positiva humana que probibe tal unión"115. La causa de que se prohíba el matrimonio entre hermanos es que se extienda la caridad a personas diferentes de los propios parientes. Ocurre que mediante el matrimonio los hombres y mujeres suelen quererse con un afecto mayor que el que tendrían si no mediara dicho pacto. Esto no sucede entre parientes, que ya se quieren con un afecto mayor al de la gente común. Por ende, "tienen una causa de afecto recíproco que los extraños no tienen" $" 16$. De forma que se prohíbe el matrimonio entre parientes, para que el amor se extienda también a los no parientes.

\section{Conclusiones}

La existencia de verdaderos matrimonios entre los americanos permitió a Alonso defender la causa indígena y poner de relieve la racionalidad de los indios. Para el agustino, la diversidad cultural no era signo de bestialidad o insensatez, sino una prueba de que los hombres se desarrollan en la historia y en el tiempo y de que adoptan ritos y formas cultuales que explican su necesidad natural de asociarse con otros bajo ciertas estructuras de poder. Pagden, comentando la tesis de Veracruz, señala que la realidad indígena no era muy distinta a la del campesino español: cuando los indios o los campesinos no vivían en auténticas politias, debían ser regidos por otros. Pero una vez que se reunían en agrupaciones políticas y se albergaban en ciudades, su capacidad para gobernarse aparecía inmediatamente ${ }^{117}$.

Es de notar que el reconocimiento que hace Alonso de la racionalidad de los

113 Ibíd., II, a. 27, p. 395.

114 Ibíd., II, a. 22, p. 337.

115 Ibíd., II, a. 27 , p. 395.

116 Ibíd., II, a. 27, p. 397.

117 Pagden, Anthony, The Fall of Natural Man. The American Indian and the Origins of Comparative Ethnology (Cambridge, Cambridge University Press, 1982), p. 98. 
indios y de su capacidad para gobernarse es un eco de la doctrina de la Escolástica española sobre la ley natural, y es una proyección ampliativa del humanismo renacentista ${ }^{118}$.

El matrimonio es un contrato y, como tal, se conforma por elementos esenciales y elementos accidentales o cambiantes. Al igual que en todo contrato, cuando el consentimiento se presta sin error y de buena fe, se origina una auténtica fuente de obligaciones para las partes ${ }^{119}$.

La estrategia de Alonso ha sido la defensa de la libertad de los indios. Por eso, en ocasiones, se torna confuso y parece contradecir sus propias conclusiones. No hay que perder de vista que el agustino no quiere redactar una Summa sobre el matrimonio. Su motivación no es teórica o filosófica. Alonso no está escribiendo un texto académico. Simplemente quiere rescatar el núcleo de racionalidad que existe en los actos y contratos celebrados por los amerindios.

\section{BiBLIOGRAFÍA}

\section{Fuentes}

Veracruz, Alonso de, Speculum coniugiorum (México, Universidad La Salle, 20092013).

-- De anima. Investigación filosófico-natural. Los libros del alma (México DF, Universitaria, 1942).

-- Elenchorum. Libro de los elencos sofísticos (México DF, Unam, 1989).

-- De decimis, (México DF, Organización de los Agustinos de Latinoamérica, 1994).

-- De dominio infidelium et iusto bello. Sobre el dominio de los infieles y la guerra justa (México DF, Unam, 2007).

Bibliografía secundaria

Aspe, Virginia, Del viejo al nuevo mundo: el tránsito de la noción de dominio y derecho natural de Francisco de Vitoria a Alonso de la Veracruz, en Revista Española de Filosofía Medieval, 17 (2010), pp. 143-155.

AzNar Gil, Federico, El nuevo derecho matrimonial canónico (Salamanca, Universidad Pontificia de Salamanca, 1984).

Bañares, Juan Ignacio, Comentario al canon 1091, en MarzoA, Ángel; Miras, Jorge y Rodríguez-Ocaña, Rafael (coords.), Comentario exegético al Código de Derecho Canónico (Pamplona, Eunsa, 2002), III/2, pp. 1200-1203.

Basalenque, Diego, Historia de la provincia de San Nicolás Tolentino de Michoacán de la orden de nuestro padre San Agustín (México DF, Jus, 1963).

Belda Plans, Juan, La Escuela de Salamanca y la renovación de la teología en el siglo XVI (Madrid, BAC, 2000).

Beuchot, Mauricio, La querella de la conquista. Una polémica del siglo XVI (México DF, Siglo XXI, 2004).

-- Filosofía y culturas novohispanas (México DF, Unam, 1998).

118 Velasco, Ambrosio, Radicalización, cit. (n. 15), p. 186.

119 Veracruz, Alonso de, Speculum, cit. (n. 17), III, a. 18, p. 285. 
-- Historia de la filosofía en el México colonial (Barcelona, Herder, 1997).

BoCCAFOlA, Kenneth, Gli impedimenti relativi ai vincoli etico-giuridici tra le persone: afinitas, consanguinitas, publica honestas, cognatio legalis, en BONNET, Piero Antonio, y Gullo, Carlo, Diritto matrimoniale canonico (Città del Vaticano, Libreria Editrice Vaticana, 2002), I, pp. 555-568.

Burrus Ernest, The Writings of Alonso de la Vera Cruz (Rome, Jesuit Historical Institute, 1976).

-- Las Casas and Veracruz. Their Defense of the American Indians Compared, en Neue Zeitschrift für Missionswissenschaft, 22 (1966), pp. 201-212.

Cervantes de Salazar, Francisco, La Universidad de México en 1554. Tres diálogos latinos (México DF, Unam, 2001).

Cerezo de Diego, Prometeo, Alonso de la Veracruz y su maestro Francisco de Vitoria, en Velasco, Ambrosio (ed.), Fray Alonso de la Veracruz: universitario, humanista, cientifico y republicano (México DF, Unam, 2009), pp. 19-46.

Código de Derecho Canónico de 1983.

Díaz, Gonzalo, Hombres y documentos de la filosofía española (Madrid, CSIC, 1980).

Illanes, José Luis y Saranyana, Josep-Ignasi, Historia de la teología (Madrid, BAC, 1995).

García ICAZBAlCETA, Joaquín, Bibliografía mexicana del siglo XVI (México DF, FCE, 1954).

Gómez Robledo, El magisterio filosófico y jurídico de Alonso de la Veracruz (México DF, Porrúa, 1984).

Goti, Juan, El 'Speculum coniugiorum' de Alonso de Veracruz y la inculturación del matrimonio canónico en México, en Ius canonicum, 39/1 (1999), pp. 619-632.

Gracia, Jorge, Filosofia hispánica (Pamplona, Cuadernos de Anuario Filosófico, 1998).

Grijalva, Juan de, Crónica de la Orden de N.P.S. Agustín en las provincias de la Nueva España (México DF, Porrúa, 1985).

LARroyo, Francisco, La filosofía iberoamericana (México DF, Porrúa, 1989).

Medina, Yail, Ley natural y matrimonio en el Espejo de los cónyuges de Alonso de la Veracruz, en Velasco, Ambrosio (ed.), Fray Alonso de la Veracruz: universitario, humanista, cientifico y republicano (México DF, Unam, 2009), pp. 125-142.

Pagden, Anthony, The Fall of Natural Man. The American Indian and the Origins of Comparative Ethnology (Cambridge, Cambridge University Press, 1982).

Pena González, Miguel-Anxo, Fray Alonso de la Veracruz: un antecedente de la independencia americana, en ESQUIVEL, Héctor (compilador), Pensamiento novohispano (Toluca, Universidad Autónoma del Estado de México, 2011), pp. 39-65.

Pereña, Luciano, La Escuela de Salamanca, notas de identidad, en Gómez Camacho, Francisco, y Robledo, Ricardo (eds.), El pensamiento económico de la Escuela de Salamanca (Salamanca, Eusal, 1998), pp. 43-64.

Saranyana, Josep-Ignasi, Grandes maestros de la teología. De Alejandría a México (siglos III al XVI) (Madrid, Atenas, 1994).

TEJERO, Eloy, La primera valoración doctrinal del matrimonio de indios en Nueva España, en Saranyana, Josep-Ignasi, et al. (eds.), Evangelización y teología en América (siglo XVI) (Pamplona, Eunsa, 1990), pp. 1293-1308.

Velasco, Ambrosio, Alonso de la Veracruz. La tradición humanista republicana, en Revista de la Universidad de México, 46 (2007), pp. 51-55.

-- Las ideas republicanas para una nación multicultural, en PONCE, Carolina (editora), 
Innovación y tradición en fray Alonso de la Veracruz (México DF, Unam, 2007), pp. 67-77.

-- Radicalización del republicanismo salmantino en México: de fray Alonso de la Veracruz a la independencia de México, en Aspe, Virginia, y Zorroza, Idoya (eds.), Francisco de Vitoria en la Escuela de Salamanca y su proyección en Nueva España (Pamplona, Eunsa, 2014), pp. 179-195. 